\title{
A game theory perspective on product development project charters: the project manager - project sponsor relationship as an iterated Prisoner's Dilemma
}

\author{
Steven M. Muegge \\ Sprott School of Business, \\ Carleton University, \\ 1125 Colonel By Drive, \\ Ottawa, Ontario, K1S 5B6, Canada \\ Email: steven.muegge@carleton.ca
}

\begin{abstract}
The product development processes of many firms include a project charter - a document that formally authorises a product development project, establishes expectations and success criteria, and provides a project manager with authority and resources. Neither the project sponsors nor the project manager have complete and perfect knowledge; thus the project charter is the outcome of negotiation, estimation, and forecasting, by stakeholders with partially aligned and partially differing incentives - a situation that game theorists characterise as a 'mixed-motive game'. This article develops a conceptual game theory model of the project manager - project sponsor relationship, then draws on past research on analytic game theory, evolutionary game theory, and behavioural game theory to develop propositions about cooperation on project charters and implications for theory and practice. The model and propositions developed from the model contribute to our conceptual understanding of cooperation within product development organisations and the theoretical underpinnings of project management.
\end{abstract}

Keywords: project management; theory; game theory; project charter; sponsor; cooperation; project governance.

Reference to this paper should be made as follows: Muegge, S.M. (2017) 'A game theory perspective on product development project charters: the project manager - project sponsor relationship as an iterated Prisoner's Dilemma', Int. J. Project Organisation and Management, Vol. 9, No. 1, pp.57-82.

Biographical notes: Steven M. Muegge is an Assistant Professor at the Sprott School of Business at Carleton University in Ottawa, Canada, where he teaches and leads a research program within Carleton's Technology Innovation Management (TIM) program. His research, teaching, and community service interests include product development, management of product development projects, technology entrepreneurship and commercialisation, non-traditional settings for innovation and entrepreneurship (business ecosystems, communities, platforms, and interconnected systems that combine these elements), and business models of technology entrepreneurs (especially in non-traditional settings).

This paper is a revised and expanded version of a paper entitled 'A game theory perspective on project charters, plans, and internal contracts' presented at the Third Student Forum on Project Management, Ottawa Canada, 29 November 2005 . 


\section{Introduction}

Practitioner guides advocate mutual cooperation between project stakeholders as an important antecedent to project success. For example, Kerzner (2009, p.18) writes:

"Success in project management is like a three-legged stool. The first leg is the project manager, the second leg is the line manager, and the third leg is senior management. If any of the three legs fail, then even delicate balancing may not prevent the stool from toppling down."

According to Kerzner (2009, p.368), "it should be possible to encourage openness and honesty from the start from all participants". In a healthy climate of honesty, integrity and trust (p.143), the project manager provides sponsors with timely, accurate, and complete project data, and the sponsors provide the project manager with the resources, support, and authority to realise objectives. Smith (2007, p.159) writes about "a collaborative atmosphere" in which team members "have a willingness to share information and be willing to consider the larger good of the whole team, placing it above their own personal interests". According to Highsmith (2012, p.55), project organisations thrive on trust and respect, free flow of information, debate, and active participation: "When any of these components is missing or ineffective, the quality of the results suffers". Trust, according to Reinertsen (2009, p.264), is both hierarchical and lateral: "Subordinates must trust their superiors, and superiors must trust their subordinates. Peers must trust their peers and the other groups they rely upon".

Evidence from empirical research tells a somewhat different story: although some product development organisations may approach the cooperative ideal of the practitioner literature, others fall short. Project managers and project sponsors sometimes play 'political games' (Chang, 2013) that deflect goals, dissipate energy, or divert resources. Top managers sometimes withhold support from projects (Boonstra, 2013). Line managers sometimes take advantage of their position in resource management (Beringer et al., 2013). Planners knowingly employ "strategic misrepresentation" (Flyvbjerg, 2014) to influence which project proposals are implemented. Project stakeholders are motivationally complex actors with differing incentives and access to different information (Cyert and March, 1963). Neither the project sponsor nor the project manager is assured of the other's full disclosure; each is aware that both they and the other party face the temptation to withhold or alter information. Even if all stakeholders ultimately seek the long-term success of the organisation, they may not interpret information in the same way, envisage the same path to success, or assess success using the same criteria (Dougherty, 1992). Likewise, the scholarly management literatures on principal-agent theory (Jensen and Meckling, 1976; Eisenhardt, 1989), incomplete contracts (Grossman and Hart, 1986), organisational power and politics (Pfeffer, 1981, 2010), and collective action (Olson, 1965) all begin from or arrive at opportunistic self-interested individual behaviour rather than trust and mutual cooperation. With a few important exceptions (e.g., Wong et al., 2005; Smyth et al., 2010; Cheung et al., 2011; Son and Rojas, 2011; Boonstra, 2013; Chang, 2013; Flyvbjerg, 2014), the project management literature is surprisingly silent on reconciling this gap between the ideal project of the practitioner literature and the empirical reality of less-than-ideal real projects. If projects with mutual cooperation are more likely to succeed, why is mutual cooperation not universal in all project organisations? Explaining and mitigating this anomaly is one motivation for this article. 
As our starting point, we focus specifically on the formation of new product development projects and on the relationship between two project stakeholders: the project manager who leads the project team and the project sponsor who provides resources and support. The standards set out by the Project Management Institute (PMI) in the PMBOK Guide (A Guide to the Project Management Body of Knowledge) specify a project charter to formally authorise a project and establish shared understanding of expectations, followed by a project plan that documents deliverables, resource requirements, and performance measures prior to execution processes. Process documents and practitioner guides employ various alternative labels and document structures: for example, Wysocki (2013) recommends a project overview statement followed by a detailed project plan, and Cooper (2011) recommends a preliminary assessment followed by a business case. In the creation and approval of these documents, the project manager and sponsor may both face temptations to behave in ways that are not fully cooperative. For example, a project manager could inflate resource forecasts, especially if he expects the sponsor to under-resource the project, or a sponsor could demand tighter schedules, especially if she expects the project manager to over-estimate resource requirements.

Our research objective for this article has two parts:

1 develop a contingency perspective on cooperation between the project manager and project sponsor

2 develop a set of propositions about the antecedents of cooperative (rather than non-cooperative) behaviour.

We employ the conceptual apparatus of game theory to model the co-creation of project charters and project plans by project managers and sponsors. Our game theory approach is similar to Cable and Shane's (1997) theory of the relationship between venture capital investors and entrepreneurs, and Schneier's (2012) theory of secure systems, both of which developed fresh insights into cooperation in their respective domains. Similarly, we contribute new theory, open up a new line of inquiry about cooperation, and propose a set of propositions about encouraging cooperation. Furthermore, we demonstrate a game theory approach to theory-building that may be applicable to other project management research questions.

Repeated calls for the development of better project management theory are the second motivation for this article. Turner (1999, pp.329-330) writes:

\begin{abstract}
"Project management lacks a strong theoretical base. Yes, there is an extensive body of knowledge, including many familiar tools and techniques. However, the Project Management Body of Knowledge is not based on a series of premises, from which a strong, consistent theory is derived, but more on conjecture. The Body of Knowledge is based more on empirical evidence than certain knowledge....

To become a mature profession, it is necessary to develop the theoretical basis of the subject. This means ... developing a set of premises about the purpose of project management, the criteria and factors for judging and achieving success on projects, and hence what constitutes good project management practice."
\end{abstract}

Calls continue to this day for a stronger theoretical foundation (e.g., Kloppenborg and Opfer, 2002; Williams, 2005; Ahlemann et al., 2013). Histories of project management describe a domain that is largely atheoretical (Johnson, 2013). Garel (2013, p.663) 
concludes: "There is no unified theory of project management". This article is, in part, an answer to these recurring calls for better theory.

\section{Background: game theory and the Prisoner's Dilemma game}

Game theory is a mathematical approach to analysing and predicting behaviour in strategic situations. It is useful in circumstances where the outcomes of decision-makers' choices are interconnected - that is, the outcomes of one actor's choices are determined, in part, by the choices of other actors. Camerer (2003, p.465) writes: "Game theory has become the standard tool in economics, is increasingly used in biology and political science, and is sporadically used in sociology, psychology, and anthropology". Gibbons (1992) and Dixit and Skeath (2009) provide accessible introductions, and Dixit and Nalebuff (1991), Brandenburger and Nalebuff (1996), and Chakravorti (2003) are examples of applying game theory to examine the interconnected choices common in management studies.

The Prisoner's Dilemma is the most widely studied situation in game theory (Camerer, 2003). The name refers to a stylised scenario (Poundstone, 1992) where two suspects arrested by the police are separated and unable to communicate with each other. The police have insufficient evidence to obtain serious convictions unless at least one of them discloses incriminating information about the other. Each prisoner faces the dilemma of choosing between two courses of action: cooperate $(\mathrm{C})$ with their partner by keeping quiet, or defect (D) on their partner by revealing information about the crime. If both cooperate, the police will have insufficient evidence to prosecute any serious crimes, and both will receive light sentences for minor offences. If both defect, both will be convicted of serious crimes. If only one prisoner defects and the other cooperates, that prisoner will be acquitted of all crimes, while the 'sucker' who conceals information will receive an especially heavy sentence.

The Prisoner's Dilemma describes a curious clash between collective and individual rationality that has fascinated researchers for more than six decades since it was first formulated in its modern form in the early 1950s. Axelrod (1984) describes real-world Prisoner's Dilemmas in domains as diverse as international diplomacy and World War I trench tactics. Accessible surveys of Prisoners' Dilemma research and the applications of Prisoner's Dilemma research to practical problems in the biological and social science include Colman (1995), Sally (1995), Brembs (1996), Axelrod (1997), Camerer (2003), and Camerer et al. (2004).

The $2 \times 2$ payoff matrix shown in Figure 1 is a mathematical description of the Prisoner's Dilemma. There are four possible outcomes determined by the pair of choices of the row and column players: $(C, C),(C, D),(D, C)$, and $(D, D)$. The entries in the matrix are the payoffs of each outcome to each player: the prison terms (in years) of the row player and column player respectively. Prison terms are bad outcomes, so the length of the sentence is a negative value. Rational players seek to maximise payoffs. 
Figure 1 A possible Prisoner's Dilemma payoff matrix

\begin{tabular}{|c|c|c|c|}
\hline \multirow{4}{*}{ Row Player } & & \multicolumn{2}{|c|}{ Column Player } \\
\hline & & C & D \\
\hline & C & $-1,-1$ & $-10,0$ \\
\hline & $\mathrm{D}$ & $0,-10$ & $-7,-7$ \\
\hline
\end{tabular}

The Prisoner's Dilemma is a mixed motive game, meaning that player preferences are neither identical nor diametrically opposed. Each player most prefers the outcome where they defect and the other cooperates, resulting in an acquittal with no time served. Their second choice is the outcome where both cooperate (conviction on a minor crime resulting in one year in prison). Their third choice is the outcome where both defect (conviction on a major crime resulting in seven years in prison). Their last choice is the outcome where they cooperate and the other defects (conviction of a major crime with an especially harsh ten-year sentence). In the parlance of game theory, D strategies are dominant for both players; that is each receives a better payoff by choosing $\mathrm{D}$ than by choosing $\mathrm{C}$ in all situations, regardless of whether the other prisoner cooperates or defects. We say that $(\mathrm{D}, \mathrm{D})$ is an equilibrium - a natural solution to the game. Mutual cooperation $(\mathrm{C}, \mathrm{C})$ is not an equilibrium because it is unstable; both players are better off with $(C, C)$ than $(D, D)$, however both players face the temptation to defect and achieve higher individual payoffs. Yet if both defect, we are back at the $(\mathrm{D}, \mathrm{D})$ equilibrium outcome that is mutually sub-optimal to both players.

More generally, the two-player Prisoner's Dilemma is fully described by the algebraic payoff matrix shown in Figure 2. The particular value of individual payoffs may vary provided that their ordinal ranking is maintained, where $T_{i}>R_{i}>P_{i}>S_{i} i \in(1,2)$. Payoffs in the general case should be interpreted as measures of economic utility - a subjective notion that can account for each players' individual preferences for outcomes rather than objective measures of the outcomes per se (Camerer, 2003; Beach and Connolly, 2005). The general two-player Prisoner's Dilemma may be asymmetric, where the payoffs for the row player differ from those of the column player. Possible extensions to the two-player Prisoner's Dilemma include the iterated Prisoner's Dilemma (IPD) which involves multiple rounds of play, or the n-player Prisoner's Dilemma extended to $\mathrm{n}$ players where $\mathrm{n}>2$. Some variants allow for incomplete information so that a player is not fully aware of other player's actions or other aspects of the game. Other variants deliberately introduce the possibility of errors in execution ('the shaky hand') and errors in perception by including various noise terms in the systems. The extant literature on the Prisoner's Dilemma game and the antecedents of cooperation is vast, spanning thousands of behavioural experiments and many hundreds of articles. 
Figure 2 General payoff matrix of the two-player Prisoner's Dilemma game

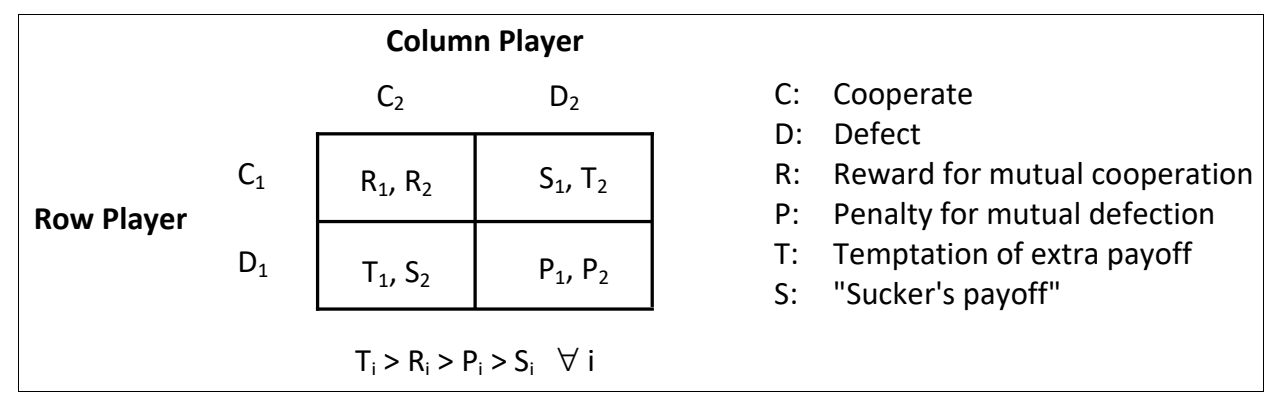

Four factors motivate the selection of the Prisoner's Dilemma as the underlying conceptual model for the project manager - project sponsor relationship in this paper. First, our review of game theory in the project management literature (summarised in the next subsection) found no comparable work on product development project charters. Second, the social science research on the Prisoner's Dilemma is amenable to theory-building. It is mature and stable, and the results are readily interpretable by non-specialists with modest effort. Third, the Prisoner's Dilemma could be an interim step to a more sophisticated conceptual model of the project manager - project sponsor relationship; we briefly discuss possible extensions in later sections. Fourth, our selection of the Prisoner's Dilemma demonstrates the feasibility of applying game theory to examine project management research questions.

\subsection{Game theory in the project management literature}

A systemic review of project management publications demonstrates the limited extent to which game theory has been used by project management researchers. Keyword searches of the International Journal of Project Management (IJPM), the Project Management Journal $(P M J)$ and the International Journal of Project Organisation and Management (IJPOM) on keywords 'game theory' OR 'Prisoner's Dilemma' OR common variants including 'prisoners dilemma' and 'prisoners' dilemma' identified three articles in which game theory is a central feature:

1 a survey of investment decision-making methods (Jovanovic, 1999)

2 a game theory model of risk allocation between public and private sectors in transportation infrastructure agreements (Medda, 2007)

3 a game-theoretic Monte Carlo simulation of road projects in the Philippines that was developed to identify advantageous concession periods for government and private partnerships (Hanaoka and Palapus, 2012).

Six additional articles (Ke et al., 2010; Smyth et al., 2010; Tang et al., 2010; Badenfelt, 2011; Cheung et al., 2011; Mohamed et al., 2011) discuss game theory in one of three ways: 
1 within a literature review

2 as an alternative approach not pursued within the current paper

3 as an opportunity for future research.

We identified eleven more articles in a broader search that included articles citing or cited by the IJPM, PMJ, and IJPOM game theory articles, a keyword search of the entire EBSCO Business Source Complete database, and a keyword search of Google Scholar. Six articles published in the Journal of Construction Engineering and Management employed game theory to examine opportunistic bidding (Ho and Liu, 2004), motivating trust in construction partnerships (Wong, 2005), the intervention decision of a government to rescue a failing infrastructure project in a public-private partnership (Ho, 2006), negotiating concession periods (Shen et al., 2007), agent-based models of temporary project teams (Son and Rojas, 2011), and review the research on public-private partnerships (Yongjian et al., 2009). The remaining five articles were each published in different journals. Meinhart and Delionback (1968) in the Academy of Management Journal employed game theory to examine incentive contracting on complex R\&D projects. Lieberman (2001), a practitioner-focused article from The Rational Edge, employed the Prisoner's Dilemma as a framework for discussing scope definition negotiations between the vendor and the client on software development projects. Neap and Aysal (2004) in the Journal of Business Ethics examines owner/client value-based decision-making in the construction industry. Martin and Songer (2004) in Construction Information Quarterly examine covenants as a possible solution to the Prisoner's Dilemma in contractually adversarial relationships. Lastly, Curiel (2011) in the International Game Theory Review employed the mathematics of cooperative game theory to examine a stylised 'project management' problem of completing of a project with multiple tasks and stakeholders.

Within this set of twenty articles, recurring themes include private-public partnerships, risk allocation, and scope change. Most prior work has examined construction projects, transportation systems, or IT deployments; only Meinhart and Delionback (1968) and Lieberman (2001) examine product development. Within the project management lifecycle, only Meinhart and Delionback (1968) and Lieberman (2001) specifically examine scope definition (rather than change or some other process group). Only Lieberman (2001), Martin and Songer (2004), and Wong et al. (2005) employ the Prisoner's Dilemma as a central framework and do so differently from our approach.

\section{Model development: the project manager - project sponsor relationship}

The constructs employed here closely follow the labels and definitions of the PMBOK Guide. Section numbers refer to the Fifth Edition (2013), however, these concepts have remained largely stable throughout all editions of the guide. 
The project manager (PM) is the person responsible for leading the team that is responsible for achieving the project's objectives [PMI, (2013), Section 1.7]. The PM coordinates and integrates project activities across multiple functional lines [Kerzner, (2009), p.10] and external stakeholders. The project sponsor (PS) is the person or group who provides resources and support for the project and is responsible for enabling success [PMI, (2013), Section 2.2.1]. Other stakeholders of a product development project may include users of the product, customers of the firm, suppliers of components or services, business partners, members of the project team, managers of team members, and others [PMI, (2013), Section 2.2.1; Wheelwright and Clark, 1992; Smith, 2007; Cooper, 2011]. However, stakeholders other than the project manager and sponsor are outside the scope of this model development.

A project charter is a document that establishes a relationship between the project manager and the project sponsor [PMI, (2013), Section 4.3]. It "documents the business needs, assumptions, constraints, the understanding of the customer's needs and high-level requirements, and the new product, service, or result that it is intended to satisfy", and may include measurable project objectives and success criteria, a summary budget, and a summary milestone schedule [PMI, (2013), Section 4.1.3]. Similar notions are found in many practitioner guides, including the product overview statement of Wysocki (2013), the preliminary assessment and business case of Cooper (2011), and the vision box, elevator test statement, and product data sheet of Highsmith (2012). Officially, it may be drafted by the project sponsor [PMI, (2013), Section 4.1.3] or by the project manager (Highsmith, 2012; Wysocki, 2013), but in practice, the content is the product of negotiation between both stakeholders (Kerzner, 2009), employing expert judgement [PMI, (2013), Section 4.1.2.2], and often assisted with facilitation [PMI, (2013), Section 4.1.2.2].

The relationships between project stakeholders and the processes for creating project artefacts all fall within the broader scope of project governance - "the alignment of the project with stakeholders' needs or objectives" [PMI, (2013), Section 2.2]. The scholarly study of project governance is said to be a 'fledging field' [Pitsis et al., (2014), p.1285] drawing on theoretical perspectives from other scholarly domains, including principalagent theory (Jensen and Meckling, 1976; Eisenhardt, 1989) examining the costs and contracts of separating ownership and control, transaction cost economics (Williamson, 1975) arguing that organisations select a governance structure that minimises the cost of transactions, shareholder theory (Friedman, 1962) focusing narrowly on maximising returns on investment for owners, stakeholder theory (Freeman, 1984; Donaldson and Preston, 1995; Miles, 2015) considering the differing interests of a broad group of constituents, stewardship theory (Donaldson and Davis, 1991; Davis et al., 1997) emphasising trust between principals and managers, and resource dependence theory (Pfeffer and Salancik, 1978) examining the power exerted by the external controllers of scarce resources. According to literature reviews and bibliometric analysis (Biesenthal and Wilden, 2014; Ahola et al. 2014), the perspectives of principal-agent theory, stakeholder theory, and transaction cost economics are particularly prominent in the nascent literature on project governance. After drawing on some conceptual arguments from stakeholder theory and principal-agent theory in the next section, the remainder of this article departs from prior project governance research by drawing exclusively on game theory and on evidence and examples from the project management literature for model development and analysis. 


\subsection{Mutual and divergent stakeholder goals}

Stakeholder theory suggests that the payoffs to the project manager and project sponsor are not identical for all possible outcomes. Both the PM and PS are likely to benefit when the firm, the product portfolio, and the project are perceived as successful. However, differences to their specific payoffs may arise from different rank orderings of priorities, magnitudes of formal incentives, and individual value judgements of the stakeholder. Likewise, principal-agent theory warns that the rational self-interest of the resource owner (i.e., the PS) and the agent managing those resources on the owner's behalf (i.e., the PM) may be only partially aligned.

Project sponsors typically occupy senior positions within organisations (Kerzner, 2009), such as the general management of a business unit. We therefore expect sponsor interests to be diversified across a portfolio of projects within their span of control. A project manager also occupies a leadership role in the organisation, but typically at a lower level than the PS. Depending on the structure of the organisation, a PM may be assigned to one project or to a small number of projects [PMI, (2013), Section 2.1.3]. In either case, the PM's personal stake in the success of their project is likely to be higher than that of the PS, whose personal stake is highest in the success of the larger portfolio rather than any single project.

Likewise, different formal incentives within the organisation may cause the PM and PS to evaluate success using different criteria. In many organisations, PM performance is assessed by comparing project results to the expectations defined in the project charter and project plan. The expectations typically include time, cost, and quality, providing the PM with strong incentives to deliver the project according to specification, on time, and on budget. PS performance is more likely to be assessed by comparing financial or strategic results of the business unit against expectations. Although project success and the success of a business unit are related, they are not identical (e.g., Brown and Eisenhardt, 1995; MacCormack et al., 2001).

Furthermore, differences of experience, knowledge specificity, and access to information may result in different value judgements and personal biases (Kahneman, 2011; Dougherty, 1992). For example, a passionate PM may genuinely believe that their project is more important than other projects to the success of the organisation, thus it would be in the interests of other stakeholders (whether they realise it or not) to assign to the project a larger share of resources. Exuberance by any stakeholder may lead to 'optimism bias' (Flyvbjerg, 2014), or temptation to commit 'creative error' (Sawyer, 1952), or over-reliance on uncertain future creativity to overcome known or suspected difficulties - what Hirschman (1967) called the 'principle of the hiding hand'.

In summary, the PM and PS appear to be motivated by some mutual goals and some potentially divergent goals, consistent with the mixed motives of the Prisoner's Dilemma game.

\subsection{Stakeholder cooperation and defection}

Examples of cooperative PM behaviour could include providing accurate and timely forecasts, allocating resources appropriately in the interests of the organisation, reporting timely and accurate project information, and involving the project sponsor appropriately. Cooperative PS behaviour may include providing the appropriate amount of management support (not too much, not too little; Wheelwright and Clark, 1995), becoming involved 
in early planning and at gates where the potential positive impact is highest (Wheelwright and Clark, 1992; Smith, 2007; Highsmith, 2012), providing adequate resources, and acting in the interests of the organisation (Kerzner, 2009). Nonetheless, the PM and PS face temptations to defect - that is, provide anything less than full cooperation and disclosure (Smyth et al., 2010; Boonstra, 2013; Chang, 2013).

A project manager could defect by over-estimating (or padding) resource forecasts to increase the likelihood that the project can be completed within the contract baselines. Alternatively, a PM could under-estimate resource requirements in order to increase the likelihood that the project would be approved at early gate reviews. These defections could occur with the best intentions for the company (Chang, 2013) or for society (Flyvbjerg, 2009); especially if the PS has a reputation for under-resourcing projects or setting impossibly high expectations, an ambitious PM may deem it better to seek forgiveness later. Examining the data on megaprojects, Flyvbjerg (2014, p.14) concludes: "It is, undoubtedly, quite common for project promoters and their planners and managers to believe their projects will benefit society and they, therefore, are justified in 'cooking' costs and benefits to get projects built" (see also Wachs, 1990; Pickrell, 1992; Flyvbjerg, 2009). Alternatively, a PM could defect by withholding bad news or inflating good news. Some buffering of information flow is part of the PM's gatekeeper role, but defection would involve overstepping those bounds for personal gain. The most extreme defections are opportunistic behaviour: for example, an unscrupulous PM could allocate project assets for their own personal gain against the interests of the sponsor.

A project sponsor could defect by deliberately under-resourcing a project. The intent may be to 'trim the fat' by correcting overly generous PM forecasts, or to allocate resources thinly in order to fund a larger number of projects (Cooper et al., 2001). The PS could over-manage the project by being too involved (perhaps related to a lack of trust), or under-manage the project by being unavailable when needed (for example, at gate reviews, or to resolve a crisis). Lastly, a PS could defect with their own opportunistic behaviour that acts against the interests of the PM and other stakeholders for personal gain.

\subsection{A Prisoner's Dilemma model of project charters}

Our model assumes that projects are managed according a structured development process with specific project phases and interim milestone deliverables and gates between phases [Cooper, 1990, 1994, 2011; Wheelwright and Clark, 1992; McGrath, 1996; PMI, (2013), Section 2.4]. The notion of a project lifecycle with different project phases is central to many product development processes [PMI, (2013), Section 2.4.1; Wysocki, 2013], regardless of whether the emphasis is on upfront planning and risk reduction (e.g., Kerzner, 2009; Cooper, 2011) or on flexibility, discovery, and adaptation (e.g., Smith, 2007; Reinertsen, 2009; Highsmith, 2012; Conforto et al., 2014).

For our purposes, we collapse the actual complexity, phases, activities, and deliverables of a real product development project into the simplified three-stage model of Figure 3. It includes at least two iterations of the Prisoner's Dilemma and an exit event that determines the success metrics for the project. 
Figure 3 A Prisoner's Dilemma model of project charters and the PM-PS relationship

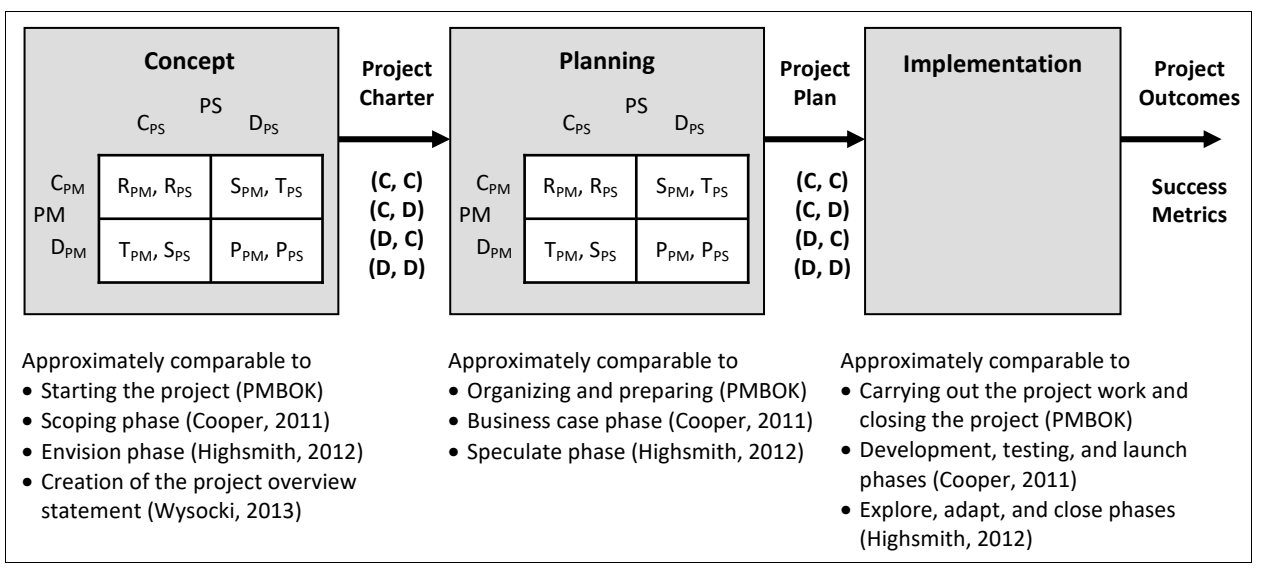

In the first stage, called concept, the PM and PS negotiate the contents of the project charter by playing one iteration of the Prisoner's Dilemma. Each may choose to cooperate (C) or defect (D). The contents of the project charter and the outcome of the Prisoner's Dilemma game become inputs to the second stage. This first stage is comparable to the 'starting the project' phase of the PMBOK Guide [PMI, (2013), Section 2.4.1], the 'scoping' phase of Cooper (2011), the 'envision phase' of Highsmith (2012), or the creation of the project overview statement of Wysocki (2013).

In the second stage, called planning, the PM and PS negotiate to expand the project charter into a more detailed project plan by playing a second iteration of the Prisoner's Dilemma. Again, each player may choose to cooperate (C) or defect (D). The contents of the project plan and the outcome of both Prisoner's Dilemma iterations become inputs to the third stage. The particular format and content of the project plan are not relevant here; the plan can be linear and predictive [Kerzner, 2009; PMI, (2013), Section 2.4.2.2] or incremental and adaptive [Smith, 2007; Reinertsen, 2009; Highsmith, 2012; PMI, (2013), Section 2.4.2.4], and may be known by different labels. The two salient features are

1 negotiation between the PM and PS

2 production of a project scope document that expands on or revises the charter.

This second stage is comparable to the 'organising and preparing' phase of the PMBOK Guide [PMI, (2013), Section 2.4.1], the 'business case' phase of Cooper (2011), or the 'speculate phase' of Highsmith (2012).

The third stage, called implementation, brings together all project activities subsequent to completion of the project plan. In our model, it is a black box that outputs project success metrics. This third stage encompasses the 'carrying out the project work' and 'closing the project' phases of the PMBOK Guide [PMI, (2013), Section 2.4.1], the 'development', 'testing', and 'launch' phases of Cooper (2011), and the 'explore', 'adapt', and 'close' phases of Highsmith (2012). This may include one or more 'scope changes' [PMI, (2013), Section 5] that re-negotiate aspects of the project charter and project plan in response to new information or new developments such as changes in the business case, and are modelled here as additional iterations of the Prisoner's Dilemma. 
The frequency and timing of negotiation interactions and communication between the PM and PS are variables that we vary in the next session.

\section{Propositions}

With the model now complete, we next apply prior research on game theory and the Prisoner's Dilemma game to develop propositions about the antecedents of project manager and sponsor cooperation and the relationship between cooperation and project outcomes. Figure 4 illustrates the hypothesised relationships between variables at the overall project level (4a), and at the microstructural level within a single iteration of the Prisoner's Dilemma (4b). At the project level [Figure 4(a)], antecedents of cooperation increase the likelihood of mutual cooperation between the project manager and sponsor over repeated play, and mutual cooperation over repeated play increases the likelihood of successful project outcomes. These relationships are expressed as propositions (P0 through P8). At the microstructural level [Figure 4(b)], each antecedent effects the decision by each stakeholder to either cooperate or defect within a single iteration of the Prisoner's Dilemma, thus effecting the expectations for future iterations of repeated play within a project.

Figure 4 A Prisoner's Dilemma model of PM-PS cooperation

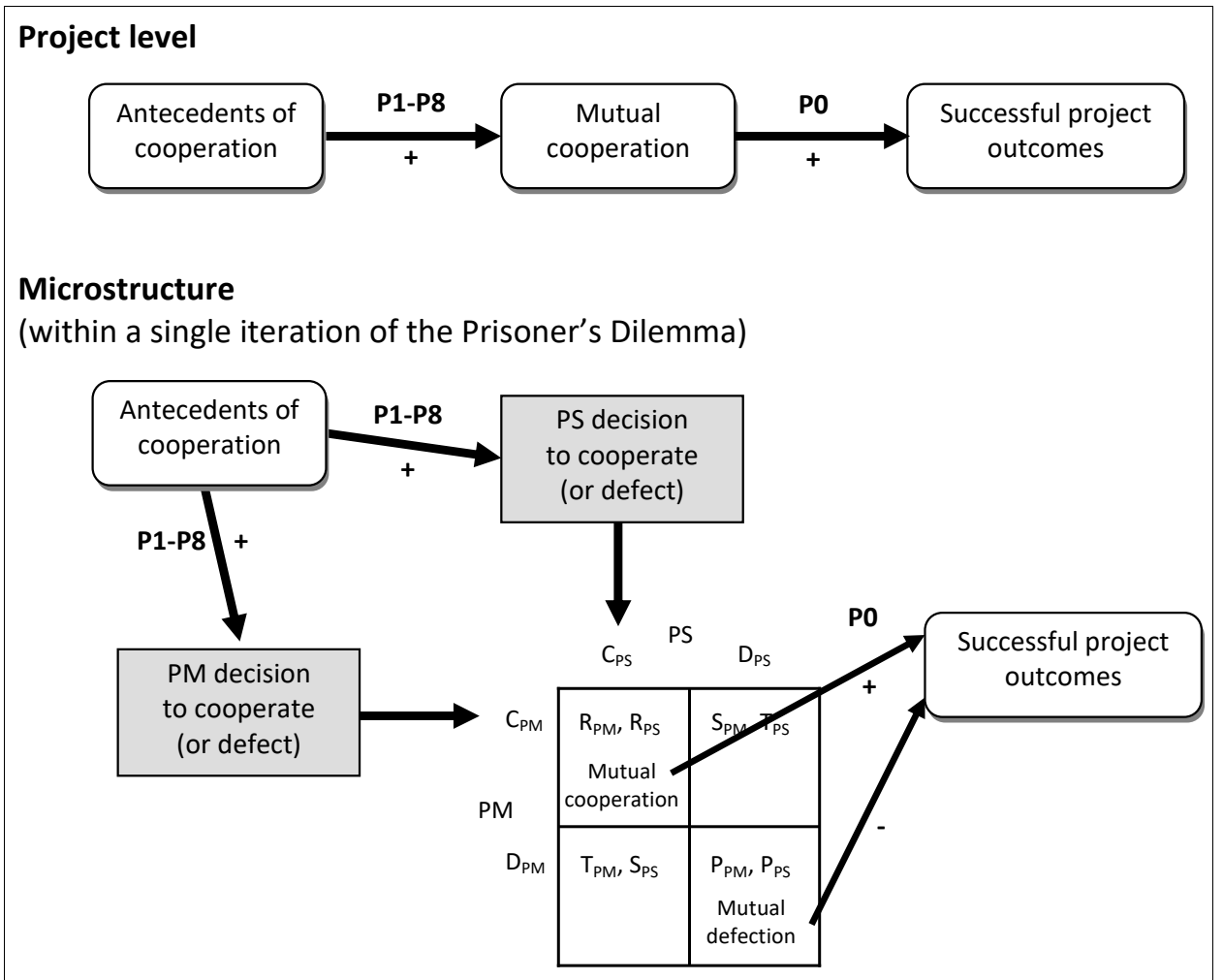


We draw on three closely related streams of Prisoner's Dilemma research analytic game theory (AGT), evolutionary game theory (EGT), and behavioural game theory (BGT) - and interpret the salient results by connecting them back to the project management body of knowledge.

$A G T$ is a prescriptive mathematical approach to the analysis of strategic interactions. It proceeds from the assumptions that all players are rational self-interested actors who seek to maximise their payoffs. AGT originates from the pioneering work of von Neumann and Morgenstern (1944) generalised by Nash (1950).

$E G T$ uses biological concepts such as survival, reproduction, heredity, mutation, learning, and spatial distance, and computer simulations of software agents to understand how cooperation evolves in iterated games. The principal EGT references for this paper are the later works by Robert Axelrod and his colleagues at the University of Michigan (Axelrod and Dion, 1988; Axelrod, 1997).

$B G T$ is a body of descriptive theory of human behaviour based on observation and psychological experiments on human subjects. It seeks to sharpen and extend AGT by suggesting realistic modifications to the assumptions of strict rationality, and thereby improve its predictive power. In particular, the behavioural evidence shows that equilibration - the process by which a system approaches equilibrium - takes time. Players have computational limitations on their capacity to calculate outcomes, learn over time as they gain experience with a game, and dislike treatment that they perceive as unfair. The principal BGT references for this paper are Colman (1995), Sally (1995), Camerer et al. (2004), Huck (2004), and Camerer (2003).

In developing our model, we have taken Crawford's (1997) advice that researchers adopt multiple game theory perspectives that consider together the results of theorising, controlled experiments, and field observations of human behaviour. We conceptually reconcile these perspectives as different aspects of the cycles of induction and deduction by which management theory is constructed and improved (Christensen and Raynor, 2003; Christensen, 2006). AGT is mainly deductive and prescriptive. BGT is mainly inductive, descriptive, and anomaly-seeking - what Camerer (2003, p.465) calls "the dialogue between theory and observation". EGT employs both deductive and inductive reasoning on simplified simulations of real phenomena.

\subsection{Alter payoff structures}

Brandenburger and Nalebuff (1996) argue that success in business comes from actively shaping the game you play - from making the game you want, not taking the game you find. Ways of altering the payoffs of Figure 3 include

1 increasing the incentives for cooperation

2 increasing the penalties for defection

3 some combination of 1 and 2.

If we alter the payoffs sufficiently such that the ordinal ranking $T_{i}>R_{i}>P_{i}>S_{i} \square i \in(1$, 2) no longer holds, the game is no longer a Prisoner's Dilemma and may have dominant strategies that intersect at a Pareto optimal equilibrium of trust. For example, altering the payoffs such that $\mathrm{R}>\mathrm{T}$ results in a game of assurance where cooperation is the dominant strategy (Dixit and Skeath, 1999). 
Experimental evidence from BGT laboratory experiments shows that player behaviour is often impacted by changes in payoff structures that do not alter the equilibrium (Goeree and Holt, 2001). Actual player behaviour may shift significantly in response to varying the magnitude of the payoffs within the ordinal ranking. This is an important result because it is not predicted by AGT. The trends are generally in-line with common-sense predictions (Colman, 1995): increasing $\mathrm{R}$ relative to $\mathrm{P}$ increases the proportion of $\mathrm{C}$, and increasing $\mathrm{T}$ relative to $\mathrm{S}$ decreases the proportion of $\mathrm{C}$. Rapoport and Chammah (1965) define a cooperation index given by the ratio $r=(R-P) /(T-S)$ as a predictor of the proportion of $\mathrm{C}$ choices, with a correlation of 0.641 between $\log \mathrm{r}$ and the proportion of C (Sally, 1995; Camerer, 2003).

Proposition 1 Higher incentives for cooperation are positively associated with cooperation.

Proposition 2 Higher penalties for defection are positively associated with cooperation.

As noted earlier, payoffs should be interpreted in the broadest possible sense as measures of economic utility. Payoffs certainly include monetary incentives and material perks, but they must also include non-pecuniary and less tangible benefits such as reputation, adherence to a moral code, or a sense of self-worth. A complete payoff function includes everything of value to a particular player, including social preferences (Fehr and Fischbacher, 2002). For example, reducing the social stigma for missing project milestones could reduce PM incentives to inflate resource requirements or padding timelines. Likewise, the organisational context and the characteristics of particular projects could alter the payoffs. For example, on a routine product development project - requiring only incremental innovation from the project team, utilising existing organisational competencies, and delivering into an established and well-understood market - defection by either the PM or PS might be more easily observed and more harshly penalised by the organisation. Conversely, on a higher risk and higher uncertainty product development project - requiring radical innovation from the project team, developing new organisational competencies, and launching into a new unproven market - defection by either the PM or PS may be harder to observe and punish, and the potential rewards may be more tempting. Alternatively, the same situation could present different payoff structures to different players; for example, a senior project manager with a proven track-record may perceive payoffs differently from a junior project manager seeking to establish a reputation.

\subsection{Repeated play}

From both analytic and behavioural perspectives, the IPD is a very different game from the one-shot Prisoner's Dilemma. In the IPD, players who defect in one round can be 'punished' by defections in subsequent rounds. The frequency of repeated play and the circumstances in which play is repeated can strongly impact the likelihood of cooperation.

If the perceived future value of cooperation exceeds the short-term gain of defection, cooperation could be a dominant rational strategy. This is managed computationally in AGT by introducing a discount factor to future payoffs, analogous to net present value calculations that consider the time value of money. Under certain conditions, AGT 
analysis shows that the equilibrium of the IPD game can shift from mutual defection to mutual cooperation. However, those strict conditions are rarely found in practice. The cooperative equilibrium, where cooperation is the dominant strategy for both players, occurs with certainty only in the limit when the IPD is infinitely repeated. If the IPD is to be repeated for a known finite number of iterations, defection remains the dominant strategy. This result follows from backwards induction: beginning analysis at the last round of play and proceeding backwards in time to the present (Dixit and Skeath, 2009). Because there are no subsequent iterations, the final iteration of the finite-length IPD is identical to the one-shot Prisoner's Dilemma, and the dominant strategy is defection. Thus the dominant strategy in the second-last iteration is also defection, and so on, back to the very first round (Gibbons, 1992). If the IPD is to be repeated for an unknown number of iterations, the analysis is more complex. In fact, the rational dominant strategy for any particular iteration depends on the players' expectations of the likelihood that play proceeds for additional iterations - a notion referred to as the shadow of the future. If the shadow of the future is long, that is, if players expect that play is very likely to continue well into the future, cooperation is more likely.

The experimental evidence of BGT suggests that cooperation is actually more likely in practice than rational AGT would predict. Also, there are strong learning effects observed during repeated play. Colman (1995) reports on a three-phase trend in laboratory experiments in long series of iterations. On the first trial, the proportion of cooperative choices is typically slightly greater than $50 \%$, but this is followed by a sobering period - a rapid decline in cooperation. After approximately 30 iterations, a recovery period sets in where cooperative choices begin to increase slowly in frequency.

These results have several implications for our project charter game. A single iteration of the model described previously in Figure 3 includes two iterations of the Prisoner's Dilemma. The dominant strategy according to backwards induction is defection at both stages. However, if that game was to be repeated with expectations by both the PM and PS that there would be subsequent iterations, cooperation could be a rational strategy. In other words, we expect cooperation to be more likely for PMs and PSs that expect to remain in their roles and to interact over multiple projects in the future. Likewise, we expect less cooperation from players anticipating no future interactions.

Proposition 3 Expectation of a longer term of incumbency is positively associated with cooperation.

In addition to the two iterations of the IPD in our simple model, it may be that the PM and PS interact with one another in other ways and at other times. Interactions that involve choices of cooperation or defection - for example, scope change requests [PMI, (2013), Section 5], milestone reviews, the re-allocation of resources outside of scheduled reviews, or other interactions on multiple projects - are modelled here as additional iterations of the IPD. Thus, from the same AGT and BGT findings about IPD repeated play (e.g., Gibbons, 1992; Colman, 1995; Dixit and Skeath, 2009), we expect a greater likelihood of cooperation with an increased frequency of IPD interactions.

Proposition 4 A greater frequency of interaction between the PM and PS is positively associated with cooperation. 


\subsection{Communication}

Communication between human players can facilitate the development of cooperation and trust in social dilemma games including the PD and IPD (Sally, 1995). Unanticipated by AGT analysis, communication effects are empirical BGT phenomena rooted in human psychology (Camerer, 2003); they can have complex and subtle nuances that may be difficult to interpret (Colman, 1995). In general, however, BGT research on PD and IPD game play reports that enabling communication between players both prior to and during the game, and increasing the duration, frequency, and richness of communication, is often associated with more frequent cooperative outcomes (Camerer et al., 2004). Thus we posit an association with communication.

Proposition 5 More communication between the PM and PS is positively associated with cooperation.

Note that proposition five about communication between players is distinct from the previous proposition about the frequency of game play interactions. Communication should be interpreted broadly to include conversations about the project, discussion about other workplace matters, and social exchanges outside of project work. No IPD game play is required for communication to occur - only the exchange of information.

\subsection{Programmed strategies}

In game theory, a programmed strategy is a particular decision rule for choosing $\mathrm{C}$ or $\mathrm{D}$ given all the available information including the results of previous IPD iterations. Computer tournaments of programmed strategies suggest four maxims of effective choice in the IPD game (Axelrod, 1980a, 1980b, 1984):

1 don't be envious of others

2 be nice (don't be the first to defect)

3 reciprocate both cooperation and defection (be both forgiving and provocable)

4 be clear (don't be too clever).

Programmed IPD strategies of unconditional cooperation and unconditional defection do not perform well in tournaments (Axelrod, 1980). This finding is consistent with BGT experiments where a proportion of human subjects would seize the opportunity of exploiting an unconditionally cooperative program (Colman, 1995). Later EGT studies (e.g. Axelrod and Dion, 1988; Axelrod, 1997) confirmed that effective programmed strategies were not merely passive; they punished defection, but not too harshly. They rewarded cooperation, but remained wary of future defections. In noisy environments where errors of interpretation and execution were possible, Axelrod (1997) found that programmed IPD strategies with some measure of generosity (a likelihood of not punishing perceived defection by responding with defection) were more effective than IPD strategies with no generosity or strategies that never punished defection. Without some generosity, a noise error between two agents with programmed strategies could result in alternating $(C, D)$ and $(D, C)$ outcomes until a second noise error occurred to break the loop. We posit that the notions of noise and generosity are important here where information is incomplete and imperfect, and either the PM or PS could misjudge 
the actions of the other player - by mistakenly perceiving cooperation as defection, or misinterpreting defection as cooperation.

Proposition 6 Moderate generosity (a likelihood of not punishing perceived defection by responding with defection) is positively associated with cooperation.

\subsection{Cultural and individual differences}

Colman's (1995) survey of BGT research concludes that cultures differ markedly with regards to the cooperativeness or competitiveness of their members. In behavioural studies of PD and IPD play, cultures that place a high value on cooperation, especially rural societies, tend to produce more cooperative citizens while cultures that encourage competitiveness produce more competitive citizens.

Organisational theorists have long argued that organisations have cultures (Schein, 2010), reinforced by rules, norms, and shared beliefs, that vary widely between different organisations (Hofstede, 2010) and even between different project-based companies (Ajmal et al., 2009). Although we are aware of no empirical studies of PD and IPD play within different organisational cultures, there is strong empirical support for a broader relationship between culture and cooperativeness, and we posit that organisational culture of a product development organisation will similarly influence cooperativeness.

Proposition 7 An organisational culture of trust and cooperation is positively associated with cooperation.

BGT studies of framing effects (Colman, 1995) demonstrate that the way in which players interpret the intentions of the other players affects the likelihood of their own cooperation. Kelley and Stahelski's (1970a, 1970b, 1970c) extensive study of attribution effects in game play found that subjects were typically predisposed to cooperative, neutral, or competitive behaviours. Cooperative and competitive people held widely differing world-views. Subjects who favoured competitive solutions were found to believe, in general, that others are uniformly competitive, whereas cooperative subjects tended to believe that some people are cooperative and others competitive. An individual's propensity to cooperate impacts cooperativeness in PD play.

Proposition 8 A player's propensity to cooperate is positively associated with cooperation.

In product development organisations with strong selection effects, Propositions 7 and 8 could potentially be mutually reinforcing over time. Project managers and sponsors with stronger propensity to cooperate would favour organisations with cooperative rules, norms, and shared beliefs, and organisations with cooperative cultures would tend to hire, retain, and promote cooperative individuals to project management and project sponsor roles.

\subsection{Outcomes of mutual cooperation}

The practitioner guides cited throughout this paper, including Smith (2007), Kerzner (2009), Reinertsen (2009), Highsmith (2012), and the PMBOK Guide (PMI, 2013), advocate mutual cooperation between the project manager and the project sponsor as an antecedent of achieving project objectives. Weaker cooperation is associated with low 
quality project results [e.g., Highsmith, (2012), p.53], with placing personal interests ahead of team interests [Smith, (2007), p.159], and with projects 'toppling down' [Kerzner, (2009), p.18]. We state this assertion here as proposition zero, where 'success' refers to the achievement of project objectives.

In our model, mutual cooperation is achieved when the PM and PS both cooperate over repeated play of the IPD game. Differential behaviours, where one player defects and the other cooperates, are unstable in repeated play and thus tend to converge over time to mutual defection (Gibbons, 1992; Colman, 1995), a Pareto-inefficient equilibrium. Proposition 0 therefore distinguishes only between mutual cooperation and all other player choices.

Proposition 0 Mutual cooperation between the project manager and project sponsor is positively associated with project success.

Our focus here in this article has been on project-level outcomes of product development projects; however, we could extend similar arguments upward to portfolio-level and business-level outcomes. For example, Flyvbjerg (2014) observed an 'inverted Darwinism' at the portfolio level - the 'survival of the unfittest' (Flyvbjerg, 2009) where projects with larger cost underestimates and benefit overestimates were implemented, while projects with more realistic forecasts did not proceed. At the business level, the resulting harm of non-cooperation may include higher direct costs, through overruns, under-performance, and non-viability, and also the opportunity costs of highervalue projects that were not implemented. A detailed treatment of portfolio-level and business-level outcomes is outside the scope of this article, but is a promising avenue for future work.

\subsection{Summary of propositions}

Table 1 is a summary of the nine propositions (see also Figure 4).

Table 1 Propositions

\begin{tabular}{|c|c|c|c|c|}
\hline & \multirow[t]{2}{*}{ Antecedent } & \multirow{2}{*}{$\begin{array}{l}\text { Project level: } \\
\text { likelihood of mutual } \\
\text { cooperation (both } \\
\text { stakeholders) }\end{array}$} & \multicolumn{2}{|c|}{$\begin{array}{c}\text { Microstructure: likelihood of } \\
\text { cooperation by each stakeholder } \\
\text { at each interaction }\end{array}$} \\
\hline & & & Project manager & Project sponsor \\
\hline $\mathrm{P} 1$ & Incentives for cooperation & + & + & + \\
\hline $\mathrm{P} 2$ & Penalties for defection & + & + & + \\
\hline P3 & Term of incumbency & + & + & + \\
\hline P4 & Frequency of interaction & + & + & + \\
\hline P5 & Communication & + & + & + \\
\hline P6 & Generosity (moderate levels) & + & + & + \\
\hline P7 & Culture of cooperation & + & + & + \\
\hline P8 & Player's propensity to cooperate & + & + & + \\
\hline P0 & \multicolumn{4}{|c|}{$\begin{array}{l}\text { Mutual cooperation between the project manager and project sponsor is } \\
\text { positively associated with project success. }\end{array}$} \\
\hline
\end{tabular}




\section{Discussion}

This article makes two contributions to project management theory and practice, each related to one of the motivations identified in the introduction. The first contribution is a partial explanation for the anomaly observed between the project management practitioner guides recommending mutual cooperation and full disclosure of information with reports in the empirical research of less-than-full cooperation. Our explanation addresses both parts of the research objective defined previously. First, we developed a contingency perspective on cooperation between the project manager and project sponsor. Second, we developed a set of propositions about the antecedents of cooperative (rather than non-cooperative) behaviour.

Our contingency perspective is briefly summarised as follows. The expectations for a new product development project are the outcome of negotiation between a project sponsor (representing the senior management of a sponsoring organisation) and a project manager (representing and leading the product development team), and are recorded in a project charter created early in the project lifecycle (Kerzner, 2009; PMI, 2013). The project charter negotiations resemble a Prisoner's Dilemma game (Poundstone, 1992; Colman, 1995; Camerer, 2003); both stakeholders benefit when the other cooperates, but each faces temptations to defect (that is, provide anything less than full cooperation). To increase the likelihood of mutual cooperation, we can alter the project charter 'game' and the context in which the game is played in ways analogous to those that improve the likelihood of cooperation of players in a Prisoner's Dilemma.

Our propositions were presented previously in Table 1. According to our results, mutual cooperation between project managers and project sponsors is more likely on product development projects and within product development organisations with specific characteristics. Many of these characteristics are actionable and prescriptive:

- reward cooperation in ways that are meaningful for each stakeholder

- penalise non-cooperative behaviour, but not too harshly

- $\quad$ retain project managers and project sponsors for long tenures to allow cooperation to evolve through repeated interaction over multiple projects

- $\quad$ promote frequent communication and frequent interaction between the project manager and sponsor, especially at the earliest stages of a project

- foster an organisational culture where cooperation and trust are the accepted norms of behaviour

- $\quad$ recruit and promote people with a propensity to cooperate, especially to project manager and sponsor positions.

The propositions of Table 1 and their managerial implications are consistent with a subset of the advice found in the PMBOK Guide and best practices in the project management and product development literature, thus providing theoretical explanations for practitioner knowledge.

The second contribution is to the theoretical underpinning of the project management profession, answering the recurring calls of Turner (1999), Kloppenborg and Opfer (2002), Williams (2005), Ahlemann et al. (2013), and others for better theories of project management that advance the body of knowledge beyond conjecture, empirics, heuristics, 
and best practices. Project management theory need not be unique to project management. Our approach builds new theory of project management by borrowing and applying mature theory from other fields of inquiry to the research problems of our own profession. Others can use this contribution in various ways: as a practical 'mental model' for enacted theory by managers in the field (Senge, 2006), as a conceptual building-block for future theory-building research (Christensen and Raynor, 2003), and as a source of hypotheses and frameworks for empirical studies.

Our use of game theory adds to the small corpus of project management research that employs Prisoner's Dilemma and other game theory analogies. We depart from past game theory work on contracts between project organisations (Martin and Songer, 2004; Wong et al., 2005) and project scope change (Lieberman, 2001) to open up a new line of game theoretic inquiry about cooperation. Likewise, we depart from past studies of project management cooperation that reject rational explanations in favour of social constructions, such as Smyth et al. (2010, p.117), which concludes: "Rational explanations of trust are shown wanting, calculations of trust and danger being misrepresentations of how the willingness to trust is formed". For interpretive researchers such as Smyth, our game theory explanation provides a rational and behavioural foil (Freeman, 1999): a baseline of strong theory from which to show how one's own perspective of cooperation departs from and improves on alternatives.

Our work has at least three limitations. First, the model and its propositions are untested. This is consistent with the stated objective of building new theory that develops the theoretical base of the project management discipline. For the theory to improve, however, predictions must be specified in a falsifiable form, and then subjected to empirical test through iterative cycles of theory-building (Christensen and Raynor, 2003; Christensen, 2006). That important work is outside the scope of this paper.

Second, by anchoring around the Prisoner's Dilemma, the theory developed here inherits all of the limitations of the Prisoner's Dilemma. We recognise that the Prisoner's Dilemma is, at best, an incomplete approximation of the complexities of the project manager - project sponsor relationship. As Milgrom (1984, pp.308-309) observed: "However appealing the Prisoners' Dilemma may be, it is just one game, just one paradigm, and it is a rather poor representation of many mixed-motive situations. A study of the Prisoners' Dilemma alone can only be suggestive”. More recently, Camerer (2003, p.46) writes: "PD and public good games are important in economic life, but they are blunt tools for guiding theories of social preference". We acknowledge that a Prisoner's Dilemma model is a vast simplification of a complex system with multiple stakeholders, a range of possible actions, incomplete information, success conditions that may differ from mutual cooperation, and more than four simple outcomes.

Third, in pursuit of parsimony, much that may be important has been excluded. We have considered only two project stakeholders, one level of analysis, and a binary choice of cooperation or defection. We have not addressed the full range of possible choices, the interests of other stakeholders, non-cooperation that benefits the organisation (Boonstra, 2013), 'collusive' cooperation between the PM and PS that harms the product development organisation or the interests of other stakeholders (Flyvbjerg, 2014), interactions within project sponsor committees that are not unitary actors, or the full impact of imperfect, incomplete and asymmetrical information and attribution. We have emphasised outcomes at the project-level, and attended less to portfolio management outcomes or business outcomes. We are also reminded of Brandenburger and Nalebuff's 
(1996) insight that every game is embedded within a larger game with different players, values, rules, tactics, and scope.

There are at least three opportunities for future work. First, we can seek to test the propositions implied by our explanation, either by systematically re-examining existing datasets in the best practices literature, or developing new empirical studies of product development organisations. Each proposition is supported by theory and modelling, but validity in any particular product development setting is an empirical question. Field work may reveal anomalies or nuances to be explained. Field data is needed to estimate effect sizes; measurement of effect sizes would enable rankings of which factors and best practices matter most. Second, we could enrich our model, sharpen our propositions, and expand the scope of our propositions by enfolding other ideas and refinements from game theory, and from the extensive literature on trust, cooperation, and voluntary contribution outside of game theory, such as commons governance (Ostrom, 1990, 2009) and peer production of community-developed assets (Benkler, 2011; Muegge, 2011, 2013). Third, we could expand our model into a more sophisticated treatment of project management governance and stakeholder relationships. We have focused here on the creation of project charters, but there are other project management interactions with interconnected payoffs, including the outcome of project gate reviews, decisions to escalate issues, negotiation over scope changes, choices about project governance, and strategic interactions at other levels of the organisation, such as the product line or the product line portfolio. The risk of extensions is loss of parsimony - a compelling strength of the current model - in exchange for theoretical richness.

\section{Conclusions}

In response to recent calls to develop the theoretical underpinnings of project management, we have developed a game theory model of the project manager - project sponsor relationship, and a contingency explanation of mutual cooperation on projects. We offer this as a contribution to the theoretical base of the project management profession.

In closing, we urge researchers pondering problems within the project management domain to consider game theory as a possible modelling and theory-building framework. Interdependencies and interconnected choices are facts of life in the project manager's world. Many real situations have elements of both cooperation and competition, and game theory offers practical and actionable insights into achieving outcomes that maximise the former and minimise the latter.

\section{References}

Ahlemann, F., El Arbi, F., Kaiser, M.G. and Heck, A. (2013) 'A process framework for theoretically grounded prescriptive research in the project management field', International Journal of Project Management, Vol. 31 No. 1, pp.43-56.

Ahola, T., Ruuska, I., Artto, K. and Juala, J. (2014) 'What is project governance and what are its origins?', International Journal of Project Management, Vol. 32, No. 8, pp.1321-1332.

Ajmal, M.M., Kekale, T. and Koshinen, K.U. (2009) 'Role of organizational culture for knowledge sharing in project environments', International Journal of Project Organization and Management, Vol. 1, No. 4, pp.358-374. 
Axelrod, R. (1980a) 'Effective choice in the prisoner's dilemma', Journal of Conflict Resolution, Vol. 24, No. 1, pp.3-26.

Axelrod, R. (1980b) 'More effective choice in the prisoner's dilemma', Journal of Conflict Resolution, Vol. 24, No. 3, pp.379-404.

Axelrod, R. (1984) The Evolution of Cooperation, Basic Books, New York.

Axelrod, R. (1997) The Complexity of Cooperation, Princeton University Press, Princeton.

Axelrod, R. and Dion, D. (1988) 'The further evolution of cooperation', Science, Vol. 242, No. 4884, pp.1385-1390.

Badenfelt, U. (2011) 'Fixing the contract after the contract is fixed: a study of incomplete contracts in IT and construction projects', International Journal of Project Management, Vol. 29, No. 5, pp.568-576.

Beach, L.R. and Connolly, T. (2005) The Psychology of Decision Making: People in Organizations, 2nd ed., Sage Publications, Thousand Oaks, CA.

Benkler, Y. (2011) The Penguin and the Leviathan: The Triumph of Cooperation Over Self-Interest, Crown Business, New York.

Beringer, C., Jonas, D. and Kock, A. (2013) 'Behavior of internal stakeholders in project portfolio management and its impact on success', International Journal of Project Management, Vol. 31, No. 6, pp.830-846.

Biesenthal, C. and Wilden, R. (2014) 'Multi-level governance: trends and opportunities', International Journal of Project Management, Vol. 32, No. 8, pp.1291-1308.

Boonstra, A. (2013) 'How do top managers support strategic information system projects and why do they sometimes withhold support?', International Journal of Project Management, Vol. 41, No. 4, pp.498-512.

Brandenburger, A.M. and Nalebuff, B.J. (1996) Co-opeticion, HarperCollinsBusiness, London.

Brembs, B. (1996) 'Chaos, cheating and cooperation: potential solutions to the Prisoner's Dilemma', OIKOS: A Journal of Ecology, Vol. 76, No. 1, pp.14-24.

Brown, S. and Eisenhardt, K. (1995) 'Product development: past research, present findings, and future directions', Academy of Management Review, Vol. 20, No. 2, pp.434-378.

Cable, D.M. and Shane, S. (1997) 'A Prisoner's Dilemma approach to entrepreneur-venture capitalist relationships', Academy of Management Review, Vol. 22, No. 1, pp.142-176.

Camerer, C.F. (2003) Behavioural Game Theory: Experiments in Strategic Interaction, Princeton University Press, Princeton.

Camerer, C.F., Loewenstein, G. and Rabin, M. (2004) Advances in Behavioral Economics, Princeton University Press, Princeton.

Chakravorti, B. (2003) The Slow Pace of Fast Change, Harvard Business School Press, Boston.

Chang, C.L. (2013) 'The relationship among power types, political games, game players, and information system project outcomes - a multiple case study', International Journal of Project Management, Vol. 31, No. 1, pp.57-67.

Cheung, S.O., Wong, W.K., Yiu, T.W. and Pang, H.Y. (2011) 'Developing a trust inventory for construction contracting', International Journal of Project Management, Vol. 29, No. 2, pp.184-196.

Christensen, C.M. (2006) 'The ongoing process of building a theory of disruption', Journal of Product Innovation Management, Vol. 23, No. 1, pp.39-55.

Christensen, C.M. and Raynor, M.E. (2003) 'Why hard-nosed executives should care about management theory', Harvard Business Review, Vol. 81, No. 9, pp.66-74.

Colman, A.M. (1995) Game Theory and its Applications in the Social and Biological Sciences, Butterworth-Heinemann, Boston.

Conforto, E.C., Salum, F., Amaral, D.C., da Silva, S.L. and de Almeida, L.F.M. (2014) 'Can agile project management be adopted by industries other than software development?', Project Management Journal, Vol. 45, No. 3, pp.21-34. 
Cooper, R.G. (1990) 'Stage-gate systems: a new tool for managing new products', Business Horizons, Vol. 3, No. 3, pp.44-54.

Cooper, R.G. (1994) 'Debunking the myths of new product development', Research and Technology Management, Vol. 37, No. 4, pp.40-50.

Cooper, R.G. (2011) Winning at New Products: Creating Value Through Innovation, Basic Books, New York.

Cooper, R.G., Edgett, S.J. and Kleinschmidt, E.J. (2001) Portfolio Management for New Products, 2nd ed., Harper-Collins, New York.

Crawford, V. (1997) 'Theory and experiment in the analysis of strategic interactions', in Kreps, D. and Wallis, K. (Eds.): Advances in Economics and Econometrics: Theory and Applications, Seventh World Congress Volume 1, Cambridge University Press, Cambridge.

Curiel, I. (2011) 'Project management games', International Game Theory Review, Vol. 13, No. 3, pp.281-300.

Cyert, R.M. and March, J.G. (1963) A Behavioral Theory of the Firm, Prentice Hall, Englewood Cliffs.

Davis, J.H., Schoorman, F.D. and Donaldson, L. (1997) 'Toward a stewardship theory of management', Academy of Management Review, Vol. 22, No. 1, pp.20-47.

Dixit, A. and Nalebuff, B.J. (1991) Thinking Strategically: The Competitive Edge in Business, Politics, and Everyday Life, Norton, New York.

Dixit, A. and Skeath, S. (2009) Games of Strategy, 3rd ed., Norton, New York.

Donaldson, L. and Davis, J.H. (1991) 'Stewardship theory or agency theory: CEO governance and shareholder returns', Australian Journal of Management, Vol. 16, No. 1, pp.49-64.

Donaldson, T. and Preston, L.E. (1995) 'The stakeholder theory of the corporation: concepts, evidence, and implications', Academy of Management Review, Vol. 20, No. 1, pp.65-91.

Dougherty, D. (1992) 'Interpretive barriers to successful product innovation in large firms', Organization Science, Vol. 3, No. 2, pp.179-202.

Eisenhardt, K.M. (1989) 'Agency theory: an assessment and review', Academy of Management Review, Vol. 14, No. 1, pp.57-74.

Fehr, E. and Fischbacher, U. (2002) 'Why social preferences matter - the impact of non-selfish motives on competition, cooperation and incentives', The Economic Journal, Vol. 112, No. 478, pp.C1-C33.

Flyvbjerg, B. (2009) 'Survival of the unfittest: why the worst infrastructure gets built, and what we can do about it', Oxford Review of Economic Policy, Vol. 25, No. 3, pp.344-367.

Flyvbjerg, B. (2014) 'What you should know about megaprojects and why: an overview', Project Management Journal, Vol. 45, No. 2, pp.6-19.

Freeman, J. (1999) 'Efficiency and rationality in organizations', Administrative Science Quarterly, Vol. 44, No. 1, pp.163-175.

Freeman, R.E. (1984) Strategic Management: A stakeholder Approach, Pitman, Marshfield.

Friedman, M. (1962) Capitalism and Freedom, University of Chicago Press, Chicago.

Garel, G. (2013) 'A history of project management models: from pre-models to the standard models', International Journal of Project Management, Vol. 31, No. 5, pp.663-669.

Gibbons, R. (1992) Game Theory for Applied Economists, Princeton University Press, Princeton.

Goeree, J.K. and Holt, C.A. (2001) 'Ten little treasures of game theory and ten intuitive contradictions', American Economic Review, Vol. 91, No. 5, pp.1402-1422.

Grossman, S. and Hart, O. (1986) 'The costs and benefits of ownership: a theory of vertical and lateral integration', Journal of Political Economy, Vol. 94, No. 4, pp.691-718.

Hanaoka, S. and Palapus, H.P. (2012) 'Reasonable concession period for build-operate-transfer road projects in the Philippines', International Journal of Project Management, Vol. 30, No. 8, pp.938-949. 
Highsmith, J. (2012) Agile Project Management: Creating Innovative Products, 2nd ed., Addison-Wesley, Upper Saddle River.

Hirschman, A.O. (1967) Development Projects Observed, Brookings Institution, Washington.

Ho, S. (2006) 'Model for financial renegotiation in public-private partnership projects and its policy implications: game theoretic view', Journal of Construction Engineering and Management, Vol. 132, No. 7, pp.678-688.

Ho, S.P. and Liu, L.Y. (2004) 'Analytic model for analyzing construction claims and opportunistic bidding', Journal of Construction Engineering \& Management, Vol. 130, No. 1, pp.94-104.

Hofstede, G.H. (2010) Cultures and Organizations: Software of the Mind, 3rd ed., McGraw-Hill, New York.

Huck, S. (2004) Advances in Understanding Strategic Behaviour: Game Theory, Experiments and Bounded Rationality, Palgrave MacMillan, Basingstoke.

Jensen, M. and Meckling, W. (1976) 'Theory of the firm: managerial behavior, agency costs, and ownership', Journal of Financial Economics, Vol. 3, No. 4, pp.305-360.

Johnson, S.B. (2013) 'Technical and institutional factors in the emergence of project management', International Journal of Project Management, Vol. 31, No. 5, pp.670-681.

Jovanovic, P. (1999) 'Application of sensitivity analysis in investment project evaluation under uncertainty and risk', International Journal of Project Management, Vol. 17, No. 4, pp.217-222.

Kahneman, D. (2011) Thinking, Fast and Slow, Double Day Canada, Toronto.

Ke, Y., Wang, S., Chan, A.P.C. and Lam, P.T.I. (2010) 'Preferred risk allocation in China's public-private partnership (PPP) projects', International Journal of Project Management, Vol. 28, No. 5, pp.482-492.

Kelley, H.H. and Stahelski, A.J. (1970a) 'Social interaction basis of cooperators' and competitors' beliefs about others', Journal of Personality and Social Psychology, Vol. 16, pp.66-91.

Kelley, H.H. and Stahelski, A.J. (1970b) 'Errors in perception of intentions in a mixed-motive game', Journal of Experimental Social Psychology, Vol. 6, No. 4, pp.379-400.

Kelley, H.H. and Stahelski, A.J. (1970c) 'The inference of intentions from moves in the Prisoner's Dilemma game', Journal of Experimental Social Psychology, Vol. 6, No. 4, pp.401-419.

Kerzner, H. (2009) Project Management: A Systems Approach to Planning, Scheduling, and Controlling, 10th ed., John Wiley \& Sons, Hoboken.

Kloppenborg, T.J. and Opfer, W.A. (2002) 'The current state of project management research: trends, interpretations, and predictions', Project Management Journal, Vol. 33, No. 2, pp.5-18.

Lieberman, B. (2001) 'Project scope management: effectively negotiating change', The Rational Edge, November, No. 1, pp.1-10.

MacCormack, A., Verganti, R. and Iansiti, M. (2001) 'Developing products on "internet time": the anatomy of a flexible development process', Management Science, Vol. 47, No. 1, pp.133-150.

Martin, D.W. and Songer, A. (2004) 'Contracts versus covenants in integrated project delivery systems', Construction Information Quarterly, Vol. 6, No. 2, pp.51-55.

McGrath, M.E. (1996) Setting the PACE in Product Development, revised ed., ButterworthHeinemann, Oxford.

Medda, F. (2007) 'A game theory approach for the allocation of risks in transport public private partnerships', International Journal of Project Management, Vol. 25, No. 3, pp.213-218.

Meinhart, W.A. and Delionback, L.M. (1968) 'Project management: an incentive contracting decision model', Academy of Management Journal, Vol. 11, No. 4, pp.427-434.

Miles, S. (2015) 'Stakeholder theory classification: a theoretical and empirical evaluation of definitions', Journal of Business Ethics, forthcoming. 
Milgrom, P.R. (1984) 'Axelrod's the evolution of cooperation', Rand Journal of Economics, Vol. 15, No. 2, pp.305-309.

Mohamed, K.A., Khoury, S.S. and Hafez, S.M. (2011) 'Contractor's decision for bid profit reduction within opportunistic bidding behavior of claims recovery', International Journal of Project Management, Vol. 29, No. 1, pp.93-107.

Muegge, S.M. (2011) 'Business ecosystems as institutions of participation: a systems perspective on community-developed platforms', Technology Innovation Management Review, Vol. 1, No. 2, pp.4-13.

Muegge, S.M. (2013) 'Platforms, communities, and business ecosystems: lessons learned about technology entrepreneurship in an interconnected world', Technology Innovation Management Review, Vol. 3, No. 2, pp.5-15.

Nash, J. (1950) 'Equilibrium points in n-person games', Proceedings of the National Academy of Sciences, Vol. 36, pp.48-49.

Neap, H.S. and Aysal, S. (2004) 'Owner's factor in value-based project management in construction', Journal of Business Ethics, Vol. 50, No. 1, pp.97-103.

Olson, M. (1965) The Logic of Collective Action: Public Goods and the Theory of Groups, Harvard University Press, Boston.

Ostrom, E. (1990) Governing the Commons: The Evolution of Institutions for Collective Action, Cambridge University Press, Cambridge.

Ostrom, E. (2009) Beyond Markets and States: Polycentric Governance of Complex Economic Systems, 8 December, Prize Lecture for the 2009 Sveriges Riksbank Prize in Economic Sciences in Memory of Alfred Nobel, Stockholm, Sweden.

Pfeffer, J. (1981) Power in Organizations, Pitman, Marshfield.

Pfeffer, J. (2010) Power: Why Some People Have It - And Others Don't, Harper Business, New York.

Pfeffer, J. and Salancik, G.R. (1978) The External Control of Organizations: A Resource Dependence Perspective, Stanford University Press, Stanford.

Pickrell, D.H. (1992) 'A desire named streetcar: fantasy and fact in retail transit planning', Journal of the American Planning Association, Vol. 58, No. 2, pp.158-176.

Pitsis, T.S., Sankaran, S., Gudergan, S. and Clegg, S.R. (2014) 'Governing projects under complexity: theory and practice in project management', International Journal of Project Management, Vol. 32, No. 8, pp.1285-1290.

Poundstone, W. (1992) Prisoner's Dilemma, Anchor Books, New York.

Project Management Institute (PMI) (2013) A Guide to the Project Management Body of Knowledge (PMBOK Guide), 5th ed., Project Management Institute, Newton Square.

Rapoport, A. and Chammah, A.M. (1965) Prisoner's Dilemma: A Study in Conflict and Cooperation, University of Michigan Press, Ann Arbor.

Reinertsen, D.G. (2009) The Principles of Product Development Flow, Celeritas Publishing, Redono Beach.

Sally, D. (1995) 'Conversation and cooperation in social dilemmas: a meta-analysis of experiments from 1958 to 1992', Rationality and Society, Vol. 7, No. 1, pp.58-92.

Sawyer, J.E. (1952) 'Entrepreneurial error and economic growth', Explorations in Entrepreneurial History, Vol. 4, No. 4, pp.199-204.

Schein, E.H. (2010) Organizational Culture and Leadership, 4th ed., Jossey-Bass, San Francisco.

Schneier, B. (2012) Liars and Outliers: Enabling the Trust that Society Needs to Thrive, Wiley, Indianapolis.

Senge, P. (2006) The Fifth Discipline: The Art and Practice of the Learning Organization, revised ed., Doubleday, New York. 
Shen, L.Y., Bao, H.J., Wu, Y.Z. and Lu, W.S. (2007) 'Using bargaining-game theory for negotiating concession period for BOT-type contract', Journal of Construction Engineering and Management, Vol. 133, No. 5, pp.385-392.

Smith, P.G. (2007) Flexible Product Development: Building Agility for Changing Markets, Jossey-Bass, San Francisco.

Smyth, H., Gustafsson, M. and Ganskau, E. (2010) 'The value of trust in project business', International Journal of Project Management, Vol. 28, No. 2, pp.117-129.

Son, J. and Rojas, E.M. (2011) 'Evolution of collaboration in temporary project teams: an agent-based modeling and simulation approach', Journal of Construction Engineering \& Management, Vol. 137, No. 8, pp.619-628.

Tang, L., Shen, Q. and Cheng, E.W.L. (2010) 'A review of studies on public-private partnership projects in the construction industry', International Journal of Project Management, Vol. 28, No. 7, pp.683-694.

Turner, J.R. (1999) 'Project management: a profession based on knowledge or faith?', International Journal of Project Management, Vol. 17, No. 6, pp.329-330.

von Neumann, J. and Morgenstern, O. (1944) Theory of Games and Economic Behavior, Princeton University Press, Princeton.

Wachs, M. (1990) 'Ethics and advocacy in forecasting for public policy', Business and Professional Ethics Journal, Vol. 9, Nos. 1 and 2, pp.141-157.

Wheelwright, S.C. and Clark, K.B. (1992) Revolutionizing Product Development, The Free Press, New York.

Wheelwright, S.C. and Clark, K.B. (1995) Leading Product Development, The Free Press, New York.

Williams, T. (2005) 'Assessing and moving on from the dominant project management discourse in the light of project overruns', IEEE Transactions on Engineering Management, Vol. 52, No. 4, pp.497-508.

Williamson, O.E. (1975) Markets and Hierarchies: Analysis and Anti-Trust Implications, The Free Press, New York, NY.

Wong, P.S.P., Cheung, S.O. and Ho, P.K.M. (2005) 'Contractor as trust initiator in construction partnering - Prisoner's Dilemma perspective', Journal of Construction Engineering and Management, Vol. 131, No. 10, pp.1045-1053.

Wysocki, R.K. (2013) Effective Project Management: Traditional, Agile, Extreme, 7th ed., Wiley, Indianapolis.

Yongjian, K., ShouQing, W., Chan, A.C. and Cheung, E. (2009) 'Research trend of public-private partnership in construction journals', Journal of Construction Engineering \& Management, Vol. 135, No. 10, pp.1076-1086. 